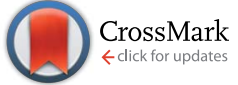

Cite this: RSC Adv., 2016, 6, 100976

\title{
Support effects on SILP hybrid catalysts prepared with carbon materials and the RhCOD complex $\uparrow$
}

\author{
M. Rufete-Beneite and M. C. Román-Martínez* \\ The Rh complex RhCOD has been immobilized on different carbon materials by means of the SILP \\ methodology (Supported Ionic Liquid Phase) with the purpose of preparing hybrid catalysts (those \\ combining the advantages of homogeneous and heterogeneous catalysis). The catalysts prepared in this \\ work have been tested in the hydrogenation of cyclohexene showing good activity, and being all of \\ them more active than an equivalent biphasic system. They are reusable without significant loss of \\ activity in at least three runs. An important effect of the support properties, related to the pore texture \\ and the surface chemistry, has been found. Likely, an appropriate combination of high supermicropore \\ volume, high mesopore volume and a reach surface chemistry leads to the best results. The obtained \\ results should stimulate analogous research on the challenging development of chiral SILP catalysts.
}

Received 5th September 2016 Accepted 11th October 2016

DOI: 10.1039/c6ra22213g

www.rsc.org/advances of that the SILP method can be of particular interest in the immobilization of molecular chiral catalysts for which the steric configuration must be highly preserved. ${ }^{23}$ On the other hand, compared to a biphasic system, which could be also a way to immobilize and recover the homogeneous catalysts, the SILP samples offer a larger interphase for the catalytic process to take place. Besides, the support surface-IL interphase plays an important role in the catalyst activity and stability.

The SILP methodology, as all hybrid catalysts preparative strategies, must face the problems usually linked to the immobilization process: instability, often related with leaching, and the potential modification of the active phase which could lead to a loss of activity and/or selectivity. In general, the textural and chemical surface properties of the support have a high influence in the performance of supported catalysts. In the case of the SILP catalysts, the support plays a relevant role, primarily, in the interaction of the active phase IL solution with the solid surface, but also in the interfacial interaction between the mentioned supported solution and the reaction media. Among the several solids that can be used as catalysts supports, ${ }^{24}$ carbon materials are particularly suitable because they can be prepared with large surface area and appropriated pore size, and their surface chemistry can be tuned. Then, this kind of supports enables a good dispersion of the active species, proper diffusion of reactants and products and the regulation of the interaction of the active species with the support. Besides, they are stable in many reaction media and expensive supported noble metals can be recovered by support combustion. Some reviews on the use of carbon materials as catalyst supports, either for common heterogeneous catalysts ${ }^{25-28}$ or for metal complexes in general ${ }^{4,5}$ can be found in the literature. There are, as well, some works dealing with the use of carbon materials to prepare SILP catalysts..$^{29-33}$
Department of Inorganic Chemistry and Materials Institute, University of Alicante, Carretera de San Vicente s/n, E-03690 Alicante, Spain.E-mail: mcroman@ua.es

$\dagger$ Electronic supplementary information (ESI) available. See DOI: $10.1039 / \mathrm{c} 6 \mathrm{ra} 22213 \mathrm{~g}$ 
In the present case, SILP catalysts have been prepared using four different carbon materials (two spherical activated carbons, a powder activated carbon and a carbon black), the ionic liquid 1-butyl-3-methyl imidazolium hexafluorophosphate ([bmim $\left.]\left[\mathrm{PF}_{6}\right]\right)$, and the Rh complex chloro(1,5-cyclooctadiene) rhodium(I) dimer, known as RhCOD. In order to investigate the catalytic properties of the prepared catalysts and to determine the effect of the support properties, the hybrid catalysts have been tested in the hydrogenation of cyclohexene in toluene, which has been selected as a test reaction. Thus, the general purpose of this work is to determine the feasibility of carbon based SILP systems by means of a test reaction, with the target of the further development of asymmetric SILP catalysts with the same supports. Also, a more specific purpose is to analyse which are the properties of the support that determine the catalytic activity and stability of the SILP hybrid catalysts.

\section{Experimental}

\section{Carbon materials description and characterisation}

The following commercial carbon materials have been used as support:

GeA: spherical shaped activated carbon prepared from a phenolic resin by Gun-ei Chemical Industry (Japan). The spheres have an average diameter of $150 \mu \mathrm{m}$.

KA: spherical shaped activated carbon produced from petroleum pitch by Kureha Corporation (Japan). The spheres have an average diameter of $780 \mu \mathrm{m}$.

$\mathrm{T}$ : carbon black T-10157 from Columbian Chemical Company (USA).

SA: powder activated carbon SA-30 from MeadWestvaco (USA).

The spherical activated carbons KA and GeA have been selected because they are very easy to manipulate. The sphere size and the textural and chemical properties of these two samples are different (see below). Carbons $\mathrm{T}$ and SA are common activated carbons used as catalysts supports. They differ in their porous structure and surface chemistry (see below).

The textural properties have been studied by gas adsorption $\left(\mathrm{N}_{2}\right.$ at $77 \mathrm{~K}$ and $\mathrm{CO}_{2}$ at $273 \mathrm{~K}$ ) after degasification (vacuum, 423 $\mathrm{K}, 5 \mathrm{~h}$ ), using an Autosorb 6-B apparatus. $\mathrm{N}_{2}$ adsorption data have been used to calculate: (i) the BET surface area, (ii) the total pore volume $\left(V_{\text {total }}\right)$ from the amount of nitrogen adsorbed at $P / P^{0}=0.99$, (iii) the micropore volume $\left(V_{\mu \mathrm{p}}\right)$ by applying the Dubinin-Radushkevich equation, and (iv) the mesopore volume (up to $7 \mathrm{~nm}, V_{\text {meso }}$ ) as the difference between the adsorbed volume at $P / P^{0}=0.90$ and at $P / P^{0}=0.20 .^{34,35} \mathrm{CO}_{2}$ adsorption data have been used to calculate the volume of narrow micropores $^{36,37}$ (diameter smaller than $0.7 \mathrm{~nm}, V_{\mathrm{n} \mu \mathrm{p}}$ ) by applying the Dubinin-Radushkevich equation. The volume of supermicropores $\left(V_{\text {sup }}(0.7 \mathrm{~nm}<d<2 \mathrm{~nm})\right)$ is obtained from the difference between micropore volume $\left(V_{\mu \mathrm{p}}\right)$ and narrow micropore volume $\left(V_{\text {n } \mu \mathrm{p}}\right)$. $^{34}$

The surface chemistry of the carbon materials has been assessed by Temperature Programmed Desorption (TPD) experiments $\left(10 \mathrm{~K} \mathrm{~min}^{-1}\right.$ in $\mathrm{He}, 100 \mathrm{~cm}^{3} \mathrm{~min}^{-1}$, up to $1273 \mathrm{~K}$ ).
The equipment used is a thermobalance TG-DTA (Mettler Toledo) coupled to a mass spectrometer (Thermostar GSD301T, Pfeiffer Vacuum).

\section{Catalysts preparation and characterization}

The catalysts were prepared with the ionic liquid 1-butyl-3methyl imidazolium hexafluorophosphate ([bmim $\left.]\left[\mathrm{PF}_{6}\right]\right)$ and the complex chloro(1,5-cyclooctadiene) rhodium(I) dimer (RhCOD) as follows: in a Schlenk apparatus, the appropriate amounts of ionic liquid (IL) and RhCOD to achieve $20 \mathrm{wt} \% \mathrm{IL}$ and $1 \mathrm{wt} \% \mathrm{Rh}$ loadings, and $2 \mathrm{~cm}^{3}$ anhydrous acetone, were added to $0.5 \mathrm{~g}$ of the outgassed support (vacuum, $423 \mathrm{~K}, 5 \mathrm{~h}$ ). The mixture was kept under Ar atmosphere and stirring until the sample took on the original dry aspect of the support.

Catalysts nomenclature is SUP20-RhCOD, where SUP accounts for the name of the support and 20 means $20 \mathrm{wt} \% \mathrm{IL}$ ([bmim $\left.]\left[\mathrm{PF}_{6}\right]\right)$ loading.

To analyse the role of the ionic liquid in the properties of the supported $\mathrm{Rh}$ complex, a catalyst was prepared without ionic liquid using support KA as follows: an acetone solution $\left(2 \mathrm{~cm}^{3}\right)$ with the necessary amount of RhCOD to achieve a $1 \mathrm{wt} \%$ Rh was added to the outgassed support and the mixture was kept in $\mathrm{Ar}$ atmosphere at room temperature with stirring to remove the solvent. This catalyst was named KA-RhCOD.

The amount of $\mathrm{Rh}$ in fresh and used catalysts was determined by ICP. The solution analysed by ICP was prepared as follows: about $30 \mathrm{mg}$ of the catalyst were treated with a mixture $\mathrm{H}_{2} \mathrm{SO}_{4}(95 \%): \mathrm{HNO}_{3}(69 \%)$ (2:1), under reflux, until the solid was completely decomposed. Then, a $1: 3 \mathrm{HNO}_{3}(69 \%): \mathrm{HCl}$ $(37 \%)$ solution was added to the flask and it was heated until the volume was reduced to approximately $3 \mathrm{~cm}^{3}$. Finally, distilled water was added up to $10 \mathrm{~cm}^{3}$. Determinations on the catalysts prepared showed that the $\mathrm{Rh}$ loading is between 0.95 and 0.98 $\mathrm{wt} \%$, and thus it can be concluded that the catalysts have the desired amount of Rh.

Fresh and used catalysts were also analysed by X-ray photoelectron spectroscopy (XPS) using a VG-Microtech Multilab 3000 equipment, and by Transmission Electron Microscopy (TEM) using a JEM-2010 JEOL microscope.

Ionic liquid leaching was investigated by thermogravimetric analysis (TG) of the used catalysts in the following conditions: heating at $10 \mathrm{~K} \mathrm{~min}^{-1}$ up to $1073 \mathrm{~K}$ in $\mathrm{N}_{2}$ flow $\left(100 \mathrm{~cm}^{3} \mathrm{~min}^{-1}\right)$, using the equipment TA Instruments 2926; the weight loss registered corresponds to the amount of ionic liquid remaining on the catalysts after its use in a catalytic activity run.

\section{Catalytic activity measurements and analysis}

Catalysts were tested in the hydrogenation of cyclohexene in toluene in the following conditions: $30 \mathrm{mg}$ catalyst, $5 \mathrm{vol} \%$ solution of cyclohexene in toluene $\left(10 \mathrm{~cm}^{3}\right)$ (S/C close to 1500), 10 bar $\mathrm{H}_{2}, 333 \mathrm{~K}$ and magnetic stirring. The stainless steel reactor was heated by means of a polyethylene glycol bath. After a reaction time of 1.5 or $5 \mathrm{~h}$, the catalysts were recovered by filtration in order to reuse them (under the same conditions) or to perform their characterisation. 
For a reference biphasic system, the catalyst was a solution of $1.5 \mathrm{mg}$ of RhCOD (amount contained in $30 \mathrm{mg}$ of the hybrid catalyst) in $0.01 \mathrm{~cm}^{3}$ of ionic liquid. A homogeneous phase test was also carried out dissolving $1.5 \mathrm{mg}$ of RhCOD in the substrate solution.

A blank experiment with $10 \mathrm{~cm}^{3}$ of a 5 vol\% solution of cyclohexene in toluene and $0.01 \mathrm{~cm}^{3}$ of ionic liquid was also performed ( $333 \mathrm{~K}, 10$ bar $\mathrm{H}_{2}, 5 \mathrm{~h}$ ). In this case no cyclohexene conversion was observed.

Analysis was performed by gas chromatography using the equipment HP6890 Series II and the column HP-1 methylsiloxane $30 \mathrm{~m} \times 250 \mu \mathrm{m} \times 0.25 \mu \mathrm{m}$. For the analysis, $0.150 \mathrm{~cm}^{3}$ of the problem solution were mixed with $0.250 \mathrm{~cm}^{3}$ acetone and $0.100 \mathrm{~cm}^{3}$ of a $7285 \mathrm{ppm}$ solution of decane (internal standard) in acetone.

GC analysis parameters are included as ESI. $\dagger$

\section{Results and discussion}

\section{Textural properties of carbon materials}

Fig. 1 shows the $\mathrm{N}_{2}$ adsorption isotherms (77 K) obtained for the four carbon materials used as support. These data reveal that they have widely different porosity developments and pore size distributions.

The $\mathrm{N}_{2}$ adsorption isotherms of samples KA and GeA are type I according to the IUPAC classification, typical of microporous

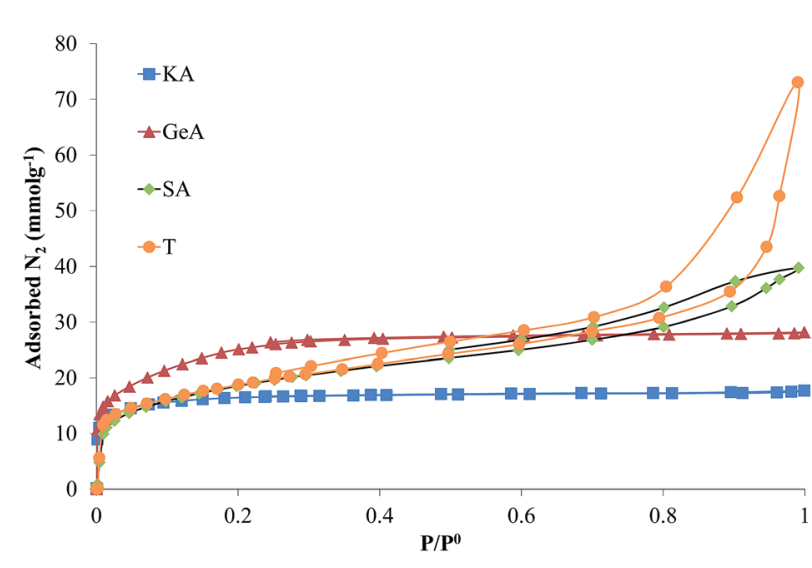

Fig. $1 \mathrm{~N}_{2}$ adsorption isotherms at $77 \mathrm{~K}$ of the carbon materials. solids. The isotherms of samples SA and T are type I + IV, characteristic of solids with micro and mesoporosity. ${ }^{35}$

Table 1 shows a summary of the textural properties calculated from $\mathrm{N}_{2}$ adsorption (77 K) and $\mathrm{CO}_{2}$ adsorption $(273 \mathrm{~K}$ ) as indicated in the Experimental section.

Although all supports have a large surface area, samples KA and GeA are essentially microporous while samples SA and T contain a significant amount of both micro and mesopores.

As previously published, ${ }^{38}$ and in agreement with what happens with other supports, ${ }^{39}$ the total pore volume determines the maximum amount of ionic liquid that these carbon materials can accept. Besides, it has been also reported ${ }^{38}$ that the loaded IL leads to some blocked porosity (not accessible to $\mathrm{N}_{2}$ ).

\section{Oxygen surface chemistry}

Table 1 also shows the amount of $\mathrm{CO}_{2}$ and $\mathrm{CO}$ evolved (in $\mu \mathrm{mol}$ $\mathrm{g}^{-1}$ ) from the different supports during TPD experiments, and the total amount of atomic oxygen (calculated from the amount of $\mathrm{CO}_{2}$ and $\mathrm{CO}$ evolved) expressed as wt\%.

Data of Table 1 show important differences between the samples. Supports GeA and SA can be pointed out as those with the richest surface chemistry, meaning this expression the largest amount of oxygen surface complexes.

The TPD profiles can be found as ESI (Fig. S1 $\dagger$ ).

\section{Activity results}

Fig. 2 shows values of cyclohexene conversion obtained with the hybrid SILP catalysts, and with the homogeneous and biphasic systems, at a reaction time of $1.5 \mathrm{~h}$. Calculated TOF data (at $t=$ $1.5 \mathrm{~h}$ and taking the active sites as moles of $\mathrm{Rh}$ from the $\mathrm{Rh}$ loading) have been also included.

It can be observed that the homogeneous system is more active than the biphasic one, what suggests that the presence of ionic liquid around the complex hinders the access of reactants to the active centre. However, all hybrid catalysts are more active than the biphasic system, and a quite important effect of the support on the catalytic activity is observed. It is striking that the catalyst prepared with the activated carbon SA is even more active than the homogeneous system.

The activity values obtained in this study are similar or even higher than those reported for this reaction in previous works

Table 1 Textural properties of the carbon material used as support and oxygen surface chemistry

\begin{tabular}{|c|c|c|c|c|c|c|c|c|c|}
\hline \multirow[b]{2}{*}{ Sample } & \multicolumn{6}{|c|}{ Textural properties } & \multicolumn{3}{|c|}{ Oxygen surface chemistry } \\
\hline & $\begin{array}{l}S_{\mathrm{BET}} \\
\left(\mathrm{m}^{2} \mathrm{~g}^{-1}\right)\end{array}$ & $\begin{array}{l}V_{\text {total }}^{a} \\
\left(\mathrm{~cm}^{3} \mathrm{~g}^{-1}\right)\end{array}$ & $\begin{array}{l}V_{\mu \mathrm{p}}{ }^{b} \\
\left(\mathrm{~cm}^{3} \mathrm{~g}^{-1}\right)\end{array}$ & $\begin{array}{l}V_{\mathrm{n} \mu \mathrm{p}^{c}} \\
\left(\mathrm{~cm}^{3} \mathrm{~g}^{-1}\right)\end{array}$ & $\begin{array}{l}V_{\mathrm{s} \mu \mathrm{p}}{ }^{d} \\
\left(\mathrm{~cm}^{3} \mathrm{~g}^{-1}\right)\end{array}$ & $\begin{array}{l}V_{\text {meso }} e \\
\left(\mathrm{~cm}^{3} \mathrm{~g}^{-1}\right)\end{array}$ & $\begin{array}{l}\mathrm{CO}_{2} \\
\left(\mu \mathrm{mol} \mathrm{g}{ }^{-1}\right)\end{array}$ & $\begin{array}{l}\mathrm{CO} \\
\left(\mu \mathrm{mol} \mathrm{g}{ }^{-1}\right)\end{array}$ & $\mathrm{O} w \mathrm{t} \%$ \\
\hline KA & 1291 & 0.67 & 0.55 & 0.44 & 0.11 & 0.05 & 291 & 167 & 1 \\
\hline GeA & 1918 & 0.98 & 0.83 & 0.50 & 0.33 & 0.10 & 790 & 960 & 4 \\
\hline SA & 1494 & 1.38 & 0.62 & 0.30 & 0.32 & 0.50 & 404 & 1720 & 4 \\
\hline $\mathrm{T}$ & 1491 & 2.53 & 0.60 & 0.34 & 0.26 & 0.58 & 179 & 505 & 1 \\
\hline
\end{tabular}

${ }^{a}$ Total pore volume, $\mathrm{N}_{2}$ volume adsorbed at $P / P^{0}=0.99 .{ }^{b}$ Micropore volume calculated by the Dubinin-Radushkevich equation applied to the $\mathrm{N}_{2}$ adsorption isotherm $(77 \mathrm{~K}) .{ }^{c}$ Narrow micropore $(<0.7 \mathrm{~nm})$ volume calculated by the Dubinin-Radushkevich equation applied to the $\mathrm{CO}_{2}$ adsorption isotherm $(273 \mathrm{~K}) .{ }^{d}$ Supermicropore $(0.7<d<2 \mathrm{~nm})$ volume calculated from the difference between micropore volume and narrow micropore volume. ${ }^{e}$ Mesopore volume calculated by the difference between the volume of adsorbed $\mathrm{N}_{2}$ at $P / P^{0}=0.90$ and $P / P^{0}=0.20$. 


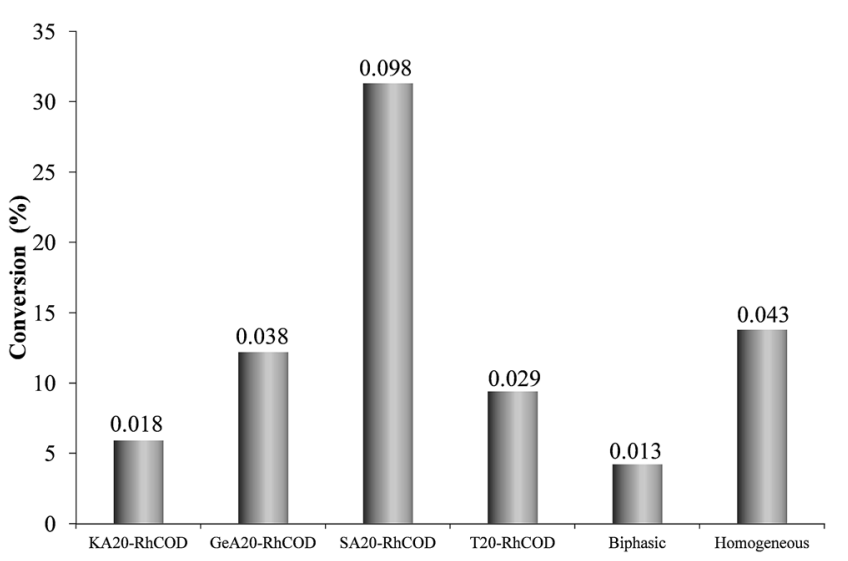

Fig. 2 Cyclohexene conversion $(\%$, bars $)$ and TOF $\left(\mathrm{s}^{-1}\right.$, values on the bars) obtained with the hybrid catalysts and with the biphasic and homogeneous systems ( 5 vol\% cyclohexene in toluene, 333 K, 10 bar $\mathrm{H}_{2}, 1.5 \mathrm{~h}$ ).

dealing with hybrid catalysts prepared with other metal complexes and supports. For example, under similar reactions conditions (toluene, $353 \mathrm{~K}, 11 \mathrm{bar}_{2}$ ), hybrid catalysts prepared by the adsorption of a Pd complex with tridecylamine ligands on carbon nanotubes, give TOF values between 0.0013 and 0.024 $\mathrm{s}^{-1}$ depending on the surface chemistry and the opening of the nanotubes. ${ }^{40}$ In similar conditions, catalysts prepared with a complex derived from the Wilkinson's catalyst and anchored by ionic exchange on different aluminosilicates, give TOF values between 0.028 and $0.036 \mathrm{~s}^{-1}$. $^{41,42}$

Nevertheless, in order to give the right value to the obtained results, it is necessary to analyse the stability of the catalysts against leaching. This study is presented in the next paragraph.

Also, it is important to determine if the hybrid catalysts are reusable. Thus, the prepared catalysts were tested in three consecutive runs (of 1.5 and $5 \mathrm{~h}$ ) to study their reusability. To reuse a catalyst, after a certain reaction time, it was removed from the reaction media by filtration and then used again in the same conditions $\left(333 \mathrm{~K}, 10 \mathrm{bar}_{2}\right.$ ). The obtained conversion data are presented in Table 2.

It can be observed that all the catalysts keep the conversion in three consecutive runs meaning that they can be considered reusable. It is also worth to mention that in most cases an almost full conversion is reached in $5 \mathrm{~h}$.

Comparison of data at 1.5 and $5 \mathrm{~h}$ reveals different kinetics for these catalysts. For example, samples GeA20-RhCOD and
T20-RhCOD give a similar conversion at $1.5 \mathrm{~h}$ but the full conversion is reached earlier with the second one. Considering data of Table 2, the order in catalytic activity of these catalysts is as follows:

$$
\begin{aligned}
\text { KA20-RhCOD } & <\text { GeA20-RhCOD }<\text { T20-RhCOD } \\
& <\text { SA20-RhCOD }
\end{aligned}
$$

Regarding catalyst KA-RhCOD, prepared without ionic liquid, the obtained cyclohexene conversion at $1.5 \mathrm{~h}$ was $16.3 \%$ (versus the average $10.9 \%$ obtained with sample KA20-RhCOD in three consecutive runs, see Table 2). However, as it will be shown later, this catalyst is less stable against Rh leaching, meaning that, likely, the process takes place partially in homogenous phase.

\section{Stability against leaching}

Ionic liquid leaching. Ionic liquid leaching was investigated by thermogravimetry (TG); by comparing the TG profiles of fresh and used catalysts it is possible to determine the amount of ionic liquid lost during the reaction (leaching). Original supports were also analysed by this way in order to have reference TG profiles.

Fig. 3 shows as an example the TG profiles obtained for catalysts SA20-RhCOD and T20-RhCOD fresh and used (in a $5 \mathrm{~h}$ catalytic test), and for the original corresponding supports.

Table 3 collects the IL leaching data determined from the TG profiles.

These data are: the amount of IL leached in each case (in $\mathrm{g}$ of IL per gram of sample) and the difference between the IL loading in original and spent samples, meaning that the actual IL loading in each spent sample is 20 minus the given data.

It can be observed that the stability of these samples against IL leaching is strongly influenced by the support properties. To study this influence, the following has been considered: assuming that the cation and the anion are located as close as possible to each other, the size of one IL unit (cation + anion) has been estimated to be approximately $0.7 \mathrm{~nm}$, so it can be expected that adsorption would be limited to happen in pores with diameter larger than $0.7 \mathrm{~nm}$. It can be also assumed that the ionic liquid retained after reaction is strongly adsorbed on the support surface, likely due to its location in small pores. Thus, it is expected that the ionic liquid would be located in micropores larger than $0.7 \mathrm{~nm}$ (supermicropores (pores with diameter between 0.7 and $2 \mathrm{~nm}$ )) or in small mesopores.

Table 2 Conversion values in 3 consecutive runs of 1.5 and $5 \mathrm{~h}$ ( 5 vol\% cyclohexene in toluene, $333 \mathrm{~K}, 10$ bar $\mathrm{H}_{2}$ )

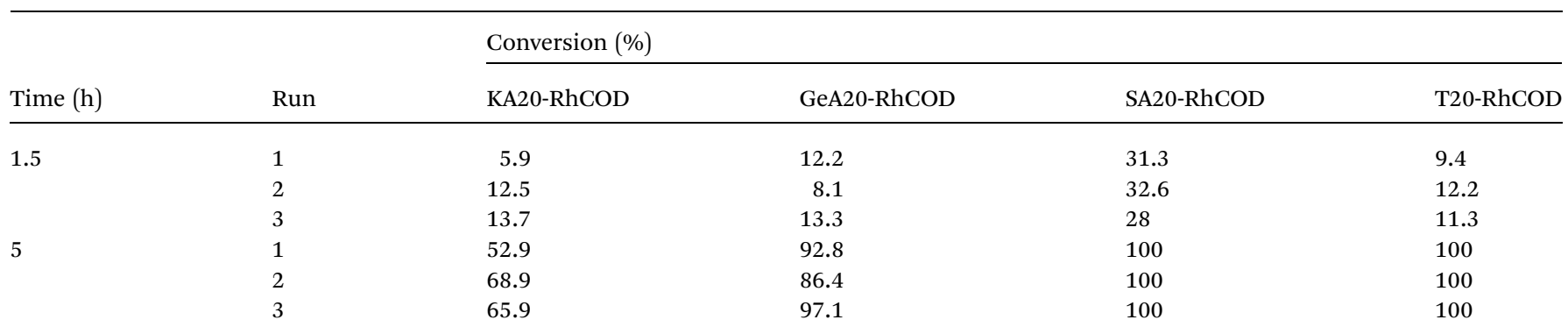



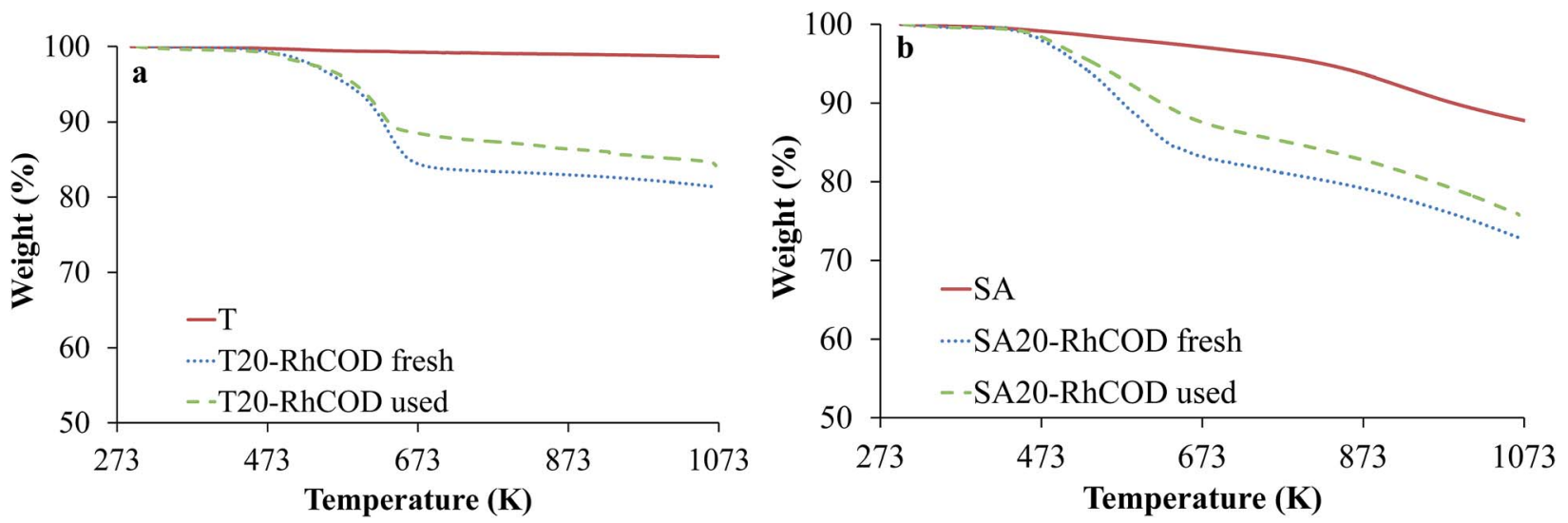

Fig. 3 TG profiles of fresh and used catalysts ( 5 vol\% cyclohexene in toluene, $333 \mathrm{~K}, 10 \mathrm{bar} \mathrm{H}_{2}, 5 \mathrm{~h}$ ), and the corresponding support: (a) T20RhCOD and T and (b) SA20-RhCOD and SA (10 K min $\left.\mathrm{K}^{-1}, \mathrm{~N}_{2} 100 \mathrm{~cm}^{3} \mathrm{~min}^{-1}\right)$.

Taking all this into account, the amount of leached IL has been plotted versus the sum of supermicropore and mesopore volumes (values included in the figure) (data of Table 1) and the graphic is shown in Fig. 4.

According to these data, there is an acceptable inverse relationship between the amount of IL leached and the volume of supermicro- and mesopores of the supports, meaning that the supports with larger volumes of supermicro- and mesopores can retain more effectively the ionic liquid. This reveals an important effect of the support porosity in the catalyst stability.

It must be mentioned that a similar plot against micropore or mesopore volumes independently didn't give a correlation between leached IL and pore volume.

Rhodium leaching. After a catalytic run, the liquid reaction media was analyzed by ICP-OES in order to determine if rhodium leaching takes place. The obtained results, shown in Table 4, are expressed as the weight percentage of $\mathrm{Rh}$ leached respect to the initial loading, and as $\mu \mathrm{mol}$ of Rh leached per gram of catalyst.

In the four SILP catalysts, Rh leaching is very low (less than $0.7 \%$ ), this amount of Rh leached would give less than $0.02 \mathrm{ppm}$ in solution. Many studies report Rh leaching in these terms and conclude that it is negligible (usually below the detection level). ${ }^{10}$ On the contrary, the catalyst prepared without IL (sample KA-RhCOD) loses $16 \%$ of the original Rh loading. These data show that the ionic liquid helps to keep the complex supported, hindering leaching. The relatively high Rh leaching of catalyst KA-RhCOD means that in this case the hydrogenation reaction could have taken place partially in homogenous

Table 3 lonic liquid leaching after use ( 5 vol\% cyclohexene in toluene, $333 \mathrm{~K}, 10$ bar $\mathrm{H}_{2}, 5 \mathrm{~h}$ )

\begin{tabular}{lll}
\hline Catalyst & Leached $\mathrm{IL}^{a}\left(\mathrm{~g} \mathrm{~g}^{-1}\right)$ & $\Delta \mathrm{IL}^{b}(\%)$ \\
\hline KA20-RhCOD & 0.093 & 9.8 \\
GeA20-RhCOD & 0.052 & 5.2 \\
SA20-RhCOD & 0.033 & 3.0 \\
T20-RhCOD & 0.033 & 3.3
\end{tabular}

${ }^{a}$ Gram of leached IL per gram of sample. ${ }^{b}$ Difference between IL loading in fresh and used samples. phase, being the reason of the higher activity of this sample commented before.

Assuming that the solution of the Rh complex in the supported ionic liquid is homogeneous and taking into account that its concentration is $0.03 \mathrm{M}$, a theoretical Rh leaching has been calculated from the IL leaching data. These values, also shown in Table 4, are much higher than those determined by analysis of the solution. The important difference between both sets of data indicates that the Rh complex is not homogeneously dissolved in the supported ionic liquid, and it can be assumed that the complex is mainly located close to the support surface with some interaction with it.

To check the effect of active phase leaching, blind tests have been carried out in some cases. After removal of the solid catalyst, fresh cyclohexene $\left(0.5 \mathrm{~cm}^{3}\right)$ was added to the solution remaining in the reactor, and then the system was submitted to the usual reaction conditions ( $\left.333 \mathrm{~K}, 10 \mathrm{bar}_{2}, 5 \mathrm{~h}\right)$. These tests have been done after using catalysts T20-RhCOD and SA20RhCOD for $5 \mathrm{~h}$. Cyclohexene conversion in the blind tests was lower than $5 \%$, what confirms that complex leaching is very low in samples prepared with IL.

\section{XPS and TEM characterization}

As reported in some cases, the anchored complex in hybrid catalysts can be partially reduced under reaction conditions. ${ }^{\mathbf{4 3 , 4 4}}$

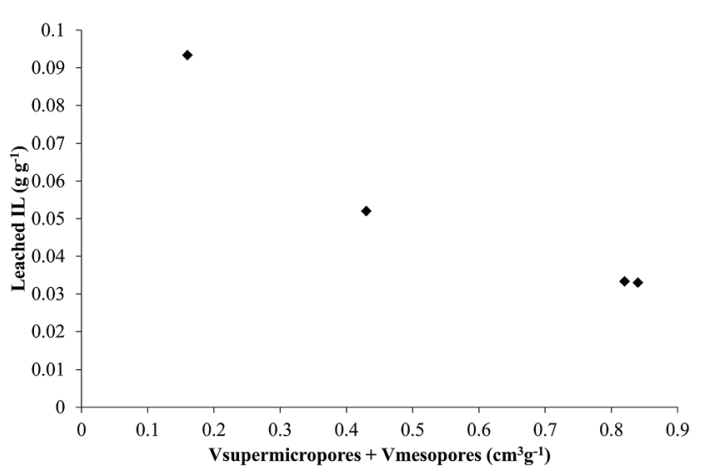

Fig. 4 Amount of leached IL vs. the micro- and mesopore volume of the supports. 
Table 4 Rh leaching upon catalysts use $(5$ vol\% cyclohexene in toluene, $333 \mathrm{~K}, 10$ bar $\mathrm{H}_{2}, 5 \mathrm{~h}$ )

\begin{tabular}{|c|c|c|c|}
\hline \multirow[b]{2}{*}{ Catalyst } & \multicolumn{2}{|c|}{ Actual Rh leaching $^{a}$} & \multirow{2}{*}{$\begin{array}{l}\text { Theoretical Rh } \\
\text { leaching }^{b}\left(\mu \mathrm{mol} \mathrm{g}^{-1}\right)\end{array}$} \\
\hline & $(\%)$ & $\left(\mu \mathrm{mol} \mathrm{g}^{-1}\right)$ & \\
\hline KA20-RhCOD & 0.24 & 0.23 & 47.46 \\
\hline KA-RhCOD & 16.00 & 15.55 & - \\
\hline GeA20-RhCOD & 0.67 & 0.65 & 26.23 \\
\hline SA20-RhCOD & 0.09 & 0.08 & 14.58 \\
\hline T20-RhCOD & 0.17 & 0.16 & 16.30 \\
\hline
\end{tabular}

${ }^{a}$ Determined by ICP. ${ }^{b}$ Calculated from the ionic liquid leaching (Table 3 ), assuming that the solution of the complex in the ionic liquid is homogeneous.

To study if such transformation also occurs in this work, some of the used catalysts ( $1.5 \mathrm{~h}$ tests) have been analysed by XPS and TEM. Fresh catalysts have been also analysed in order to have an adequate reference. The binding energy found for $\mathrm{Rh} 3 \mathrm{~d}_{5 / 2}$ (Table 5) corresponds to $\mathrm{Rh}(\mathrm{I})$ in both, fresh and used catalysts, ${ }^{48,49}$ meaning that the electronic state of Rh was not modified upon use (even after three consecutive reaction runs). However, it cannot be discarded that, as previously reported, ${ }^{44-47}$ the Rh complex could have suffered some modification related with the hydrogenation of the COD ligand.

Catalysts KA20-RhCOD and SA20-RhCOD (fresh and used) have been analysed by TEM and the obtained images are shown in Fig. 5.

Table 5 Binding energy (B.E.) of Rh $3 d_{5 / 2}$ in fresh and used catalysts ( 5 vol\% cyclohexene in toluene, $333 \mathrm{~K}, 10 \mathrm{bar} \mathrm{H}_{2}, 1.5 \mathrm{~h}$ )

\begin{tabular}{llll}
\hline Catalyst & B.E. $(\mathrm{eV})$ & Catalyst & B.E. $(\mathrm{eV})$ \\
\hline KA20-RhCODf $^{a}$ & 309.6 & SA20-RhCODf & 309.6 \\
KA20-RhCODu $^{b}$ & 309.7 & SA20-RhCODu & 309.6 \\
KA20-RhCODu3 $^{c}$ & 309.7 & SA20-RhCODu3 & 309.7 \\
GeA20-RhCODf $^{a}$ & 309.5 & T20-RhCODf & 309.8 \\
GeA20-RhCODu $^{b}$ & 309.7 & T20-RhCODu & 309.8 \\
GeA20-RhCODu3 $^{c}$ & 309.5 & &
\end{tabular}

${ }^{a}$ Fresh catalysts. ${ }^{b}$ Used catalysts. ${ }^{c}$ Catalysts used 3 consecutive runs.
The TEM images of the fresh catalysts (Fig. 5(a) and (c)) do not show characteristics different from those of the original support, indicating that the fresh catalyst contains the complex well dissolved in the supported ionic liquid. However, in the used catalysts (Fig. 5(b) and (d)) some aggregates can be observed. The composition of these aggregates is not known but it is evident that they do not present the characteristic morphology of metallic particles. Similar structures have been observed in the case of a Pd complex dissolved in a ionic liquid and they have been attributed generically to Pd aggregates in which palladium is $\mathrm{Pd}^{+}{ }^{30}$ Also in the case of Pd complexes, it has been suggested that solvent cages can be formed ${ }^{50}$ and this fact could also lead to these particular structures.

\section{Comment on the support effects}

The results presented and discussed above show that the SILP catalysts are more active than the analogous biphasic system and that they can be considered to be effective and reusable. In SILP catalysts the interface between the IL and the solvent used as reaction medium is higher than in the biphasic system and this is likely the ground of a higher activity.

The different textural, chemical and morphological properties of the carbon materials used as supports led to marked differences in the activity of the catalysts prepared with them. The catalyst prepared with support SA (commercial activated carbon) is the most active (higher conversion in shorter time). Focusing the attention on the textural properties, the obtained results point to a positive effect of a developed porosity, with a relatively high volume of supermicro- and mesopores. The role of these two kinds of pores can be related to the location of the ionic liquid solution containing the active species, and also to the favoured diffusion of the substrate to the active sites.

Support T, in spite of having a volume of supermicropores and of mesopores similar to those of carbon SA, leads to a less active catalyst. The structure of the porosity (different in carbon blacks respect to activated carbons) may have an influence, but this is difficult to be evaluated. Another aspect to take into account is the different surface chemistry of supports SA and T, being the oxygen wt $\% 4$ times higher in SA than in $\mathrm{T}$ (Table 1). Regarding this point, it should be considered that the polar/non polar interactions between the reaction media and the catalysts
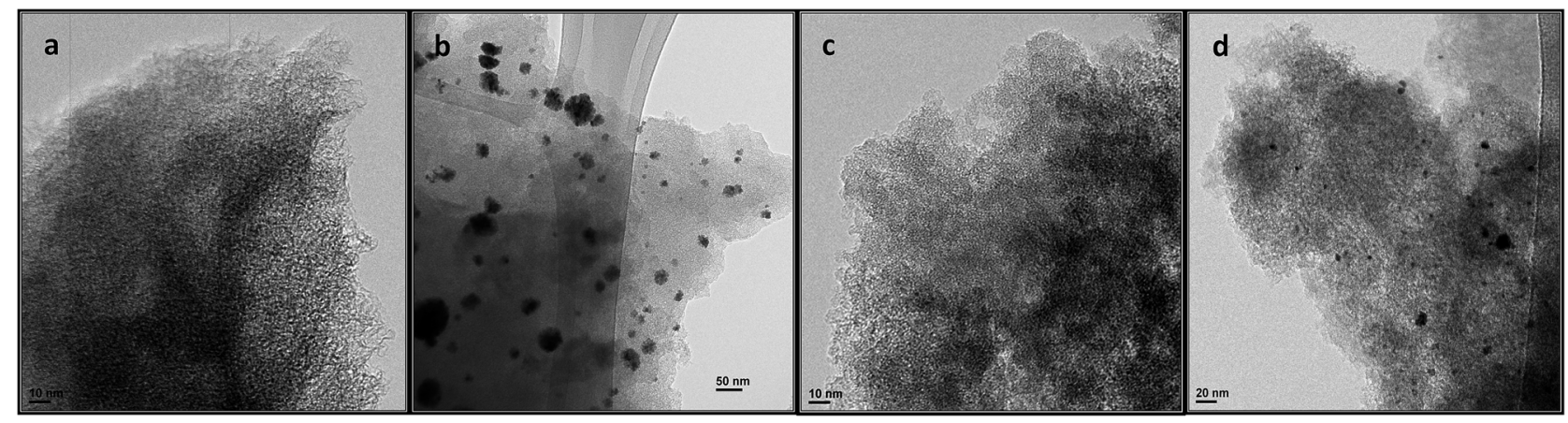

Fig. 5 TEM images of catalyst KA20-RhCOD: (a) fresh and (b) used, and catalyst SA20-RhCOD: (c) fresh and (d) used (5 vol\% cyclohexene in toluene, $333 \mathrm{~K}, 10$ bar $\mathrm{H}_{2}, 1.5 \mathrm{~h}$ ). 
may also play a role (toluene has a certain polarity). The obtained data seem to indicate that the toluene solution interacts better with catalyst SA20-RhCOD than with catalyst T20-RhCOD.

In any case, a summary of the characteristics of support SA, the one that leads to the most active catalyst are: high supermicropore volume, high mesopore volume and a rich surface chemistry. In the other supports one or the three of these variables are low and thus, likely, it is a proper combination of them what leads to the best results.

\section{Conclusions}

SILP catalysts have been prepared with the complex RhCOD and the ionic liquid [bmim] $\left[\mathrm{PF}_{6}\right]$, using several carbon materials as support. They have been tested in the hydrogenation of cyclohexene and their properties have been compared with the corresponding homogeneous and biphasic systems. The hybrid catalysts show good activity, being all of them more active than an equivalent biphasic system. They are also more active than some previously reported hybrid catalysts. It is worth noting that an important effect of the support properties has been found, and the catalyst prepared with the activated carbon SA is the most active.

Although some ionic liquid leaching takes place under reaction conditions $\mathrm{Rh}$ leaching is very low in all cases, generally lower than $1 \%$. The ionic liquid helps to the stabilization of the catalyst, hindering Rh leaching.

In used catalysts, some aggregates, with structure and composition not determined, have been detected, but the reduction to $\mathrm{Rh}(0)$ nanoparticles can be ruled out.

The catalysts are reusable without significant loss of activity in at least three runs.

The effect of the support seems to be related with the pore texture and the surface chemistry. Likely, a proper combination of high supermicropore volume, high mesopore volume and a rich surface chemistry leads to the best results.

A practical conclusion is that by selecting the appropriate carbon material, the carbon based hybrid SILP catalysts can be active, stable against Rh leaching, and reusable. Besides, these results stimulate an analogous research to develop chiral SILP catalysts.

\section{Acknowledgements}

The authors thank the MINECO and FEDER for financial support through projects MAT2012-32832 and CTQ2015-66080R, and GV for project PROMETEOII/2014/010. M. R. B. thanks the FPI scholarship grant associated to project MAT2009-07150.

\section{References}

1 Y. I. Yermakov, et al., Catalysis by Supported Metal Complexes, Stud. Surf. Sci. Cat., Elsevier, 1981, vol. 8.

2 A. Choplin, et al., Coord. Chem. Rev., 1998, 178-180, 16791702.

3 A. P. Wight and M. E. Davis, Chem. Rev., 2002, 102, 35893614.
4 C. Freire and A. R. Silva, in Carbon Materials for Catalysis, ed. P. Serp and J. L. Figueiredo, John Wiley \& Sons, Inc., New Jersey, 1st edn, 2009, ch. 8, pp. 267-308.

5 M. C. Román-Martínez and C. Salinas Martínez de Lecea, in New and Future Developments in Catalysis - Hybrid Materials, Composites, and Organocatalysts, ed. S. Suib, Elsevier, 1st edn, 2013, ch. 3, pp. 55-78.

6 M. Heitbaum, et al., Angew. Chem., Int. Ed., 2006, 45, 47324762.

7 J. M. Fraile, et al., Chem. Rev., 2009, 109, 360-417.

8 C. Copéret, et al., Chem. Rev., 2016, 323-421.

9 Y. Gu and G. Li, Adv. Synth. Catal., 2009, 351, 817-847.

10 C. Van Doorslaer, et al., Dalton Trans., 2010, 39, 8377-8390.

11 A. Riisager, et al., Top. Catal., 2006, 40, 91-102.

12 T. Selvam, A. Machoke and W. Schwieger, Appl. Catal., A, 2012, 445-446, 92-101.

13 Supported Ionic Liquids: Fundamentals and Applications, ed. R. Fehrmann, A. Riisager and M. Haumann, Wiley-VCH, 2014. 14 T. Welton, Chem. Rev., 1999, 99, 2071-2084.

15 Q. Zhang, et al., Green Chem., 2011, 13, 2619.

16 H. Olivier-Bourbigou, et al., Appl. Catal., A, 2010, 373, 1-56. 17 V. I. Pârvulescu and C. Hardacre, Chem. Rev., 2007, 107, 2615-2665.

18 P. Wasserscheid and W. Keim, Angew. Chem., Int. Ed., 2000, 39, 3772-3789.

19 J. Dupont and L. Kollár, Topics in Organometallic Chemistry, Springer, 2015, vol. 51.

20 T. Borkowski, et al., J. Catal., 2014, 319, 87-94.

21 E. García-Verdugo, P. Lozano and L. V. Santiago, in Supported Ionic Liquids: Fundamentals and Applications, ed. R. Fehrmann, A. Riisager and M. Haumann, Wiley, 2014, ch. 17, pp. 351-368.

22 R. Franke and H. Hahn, Quarterly Sciences Newsletter, Evonik Industries, 2015, pp. 18-23.

23 I. Podolean, et al., Catal. Today, 2013, 200, 63-73.

24 A. B. Stiles, Catalyst supports and supported catalysts: theoretical and applied concepts, Butterworth-Heinemann, 1987.

25 F. Rodríguez-Reinoso and A. Sepúlveda-Escribano, in Carbon Materials for Catalysis, ed. P. Serp and J. L. Figueiredo, John Wiley \& Sons, Inc., New Jersey, 1st edn, 2009, ch. 4, pp. 131156.

26 E. Auer, et al., Appl. Catal., A, 1998, 173, 259-271.

27 V. Arunajatesan, et al., in Carbon Materials for Catalysis, ed. P. Serp and J. L. Figueiredo, John Wiley \& Sons, Inc., New Jersey, 1st edn, 2009, ch. 15, pp. 535-572.

28 H. Jüntgen, Fuel, 1986, 65, 1436-1446.

29 J. P. Mikkola, et al., Ind. Eng. Chem. Res., 2007, 46, 39323940.

30 J. P. Mikkola, et al., Appl. Catal., A, 2007, 328, 68-76.

31 E. J. García-Suárez, et al., Microporous Mesoporous Mater., 2011, 144, 205-208.

32 J. J. Y. Shin, et al., Chem.-Asian J., 2011, 6, 2016-2021.

33 Y. S. Chun, et al., Chem. Commun., 2008, 942-944.

34 F. Rodríguez-Reinoso and A. Linares-Solano in Chemistry and Physics of Carbon, ed. P. Thorwer, Marcel Dekker, Inc., New York, 1989, vol. 21, pp. 1-146. 
35 F. Rouquerol, J. Rouquerol and K. Sing, Adsorption by Powders and Porous Solids. Principles, Methodology and Applications, Academic Press, London, 1999.

36 D. Cazorla-Amorós, et al., Langmuir, 1996, 12, 2820-2824.

37 D. Lozano-Castelló, et al., Carbon, 2004, 42, 1231-1236.

38 M. Rufete-Beneite, et al., Carbon, 2014, 77, 947-957.

39 J. Lemus, et al., Adsorption, 2011, 17, 561-571.

40 I. Such-Basáñez, et al., Microporous Mesoporous Mater., 2016, 225, 378-384.

41 I. Such-Basáñez, et al., Curr. Catal., 2012, 1, 100-160.

42 I. Such-Basáñez, PhD Thesis, University of Alicante, 2015.
43 C. C. Gheorghiu, et al., in Studies in Surface Science and Catalysis, ed. E. M. Gaigneaux, et al., Elsevier, 2010, vol. 175, pp. 647-651.

44 C. C. Gheorghiu, et al., ChemCatChem, 2013, 5, 1587-1597. 45 L. J. Lemus-Yegres, et al., Appl. Catal., A, 2007, 331, 26-33. 46 M. A. D. N. Perera and R. J. Angelici, J. Mol. Catal. A: Chem., 1999, 149, 99-111.

47 A. Börner and D. Heller, Tetrahedron Lett., 2001, 42, 223-225. $48 \mathrm{http}: / /$ www.lasurface.com.

$49 \mathrm{http}: / /$ srdata.nist.gov/xps/.

50 C. Sievers, et al., J. Mol. Catal. A: Chem., 2008, 279, 187-199. 